\title{
THE
}

$10-2013$

\section{Finding Their Way: How Public Library Users Wayfind}

Lauren $\mathrm{H}$. Mandel

University of Rhode Island, lauren_mandel@uri.edu

Follow this and additional works at: https://digitalcommons.uri.edu/lsc_facpubs

The University of Rhode Island Faculty have made this article openly available.

Please let us know how Open Access to this research benefits you.

This is a pre-publication author manuscript of the final, published article.

Terms of Use

This article is made available under the terms and conditions applicable towards Open Access Policy Articles, as set forth in our Terms of Use.

\section{Citation/Publisher Attribution}

Lauren H. Mandel. "Finding their way: How public library users wayfind." Library \& Information Science Research, vol. 35, no. 4, October 2013. pp. 264-271.

Available at: http://dx.doi.org/10.1016/j.lisr.2013.04.003

This Article is brought to you for free and open access by the Graduate School of Library and Information Studies at DigitalCommons@URI. It has been accepted for inclusion in Graduate School of Library and Information Studies Faculty Publications by an authorized administrator of DigitalCommons@URI. For more information, please contact digitalcommons-group@uri.edu. 


\title{
Finding Their Way: How Public Library Users Wayfind
}

\author{
Lauren H. Mandel, PhD \\ Assistant Professor \\ University of Rhode Island \\ Graduate School of Library and Information Studies
}

Preprint

\begin{abstract}
A multi-method case study research design, guided by Passini's conceptual framework of wayfinding, was employed to investigate library user wayfinding behavior within the entry area of a medium-sized public library facility. The case study research design included document review of the library's wayfinding information system; unobtrusive observation of library user wayfinding behavior; intensive interviews with library users to discuss their views on wayfinding in the Library; and an expert review with library staff and a library wayfinding and signage expert to validate research findings. Overall, the study found library users' wayfinding behavior to be generally inconsistent over time, but that there are users who stick to predominant segments (those segments used heavily to connect two particular nodes, or stops). Those segments tend to be the straightest or most direct segments connecting two given nodes. Also, users appear to employ Passini's wayfinding styles more often than his wayfinding strategies, but additional research is needed that delves more deeply into these cognitive processes.
\end{abstract}

\section{Introduction}

A public library is open to all people in a community with services offered at no charge, and the facility is the physical manifestation of a library, containing all materials, furniture, services, etc. As such, the facility is the physical expression of the library's mission and purpose, to provide information and services to users. If users cannot access and use the facility effectively, then they also cannot access and use the library's resources and services. This makes the design of public library facilities an important area of concern for public librarianship.

Wayfinding is a spatial information process that allows people to orient and navigate in the built environment. Wayfinders use a built environment's wayfinding information system as a basis for their wayfinding behavior (Arthur \& Passini, 1992), just as information-seekers use the information system of a library, catalog, or database as a basis for their information-seeking 
behavior. Therefore, wayfinding information systems must contain the information necessary to make and execute decisions along a route, such as architectural cues, linearly arranged signage, and floor plans. These systems also need to contain the information necessary for users to gain cognitive representations of the library that facilitate wayfinding. Generally, wayfinding research and theories assume that a user has an intended destination in mind when entering and navigating the facility, although effective wayfinding tools also can assist users as they meander through stacks browsing the library's collection. Such users still need wayfinding cues to suggest areas to explore (e.g., large, attractive signs that can draw a user's interest to a new area of the library or an open floor plan that allows users to see across the library from one section to another), as well as to help orient themselves and not get lost in the library.

A labyrinth is similar to a maze in its convoluted and intentionally perplexing design. However, there is a significant difference between the two puzzles. A maze is designed to make a person become lost, but a labyrinth is designed to guide a person to its center (Kern, 2000). A library should be more labyrinth than maze, with people guided to the library's center-its information, materials, resources, and services. Unfortunately, many libraries are more mazelike, or, at best, are labyrinths that lack the cues guiding people to their centers. This multimethod case study builds upon a pilot study (Mandel, 2010) with additional research questions and methods, and both serve as beginning efforts toward understanding the mazes of libraries and ways to modify those mazes into easy to navigate, intuitive labyrinths.

\subsection{Problem statement}

When a user enters a public library facility, he is confronted by at least two information problems: the information problem he hopes to address using library resources and the spatial information problem of trying to locate those resources that will help him solve his information problem. Public libraries tend to focus on helping users address their information problems without paying much attention to the spatial information users need. This means that users who may already experience library anxiety may have another level of frustration as they attempt to wayfind through the public library to solve their information needs. Despite this, the public

library facility evaluation literature focuses on collection and furniture space needs with minimal attention paid to user wayfinding needs. While such research has occurred in academic libaries, public library users differ from academic library users in important ways, such as being a more heterogenous population comprised of people of varying ages and educational background and 
attempting to solve a wide array of personal information challenges, as compared with the formal and often imposed information challenges for academic library users.

The literature that does address public library user wayfinding needs places a heavy emphasis on signage as the solution, and rarely is based on empirical research. While signage is popular in libraries and can be relatively inexpensive to modify, the architectural literature explains that signage is but one component of a facility's spatial information system and, in fact, signage cannot compensate for a confusing physical layout (Passini, 1996). It is necessary for public libraries to understand what the other components are, how users are employing those components, which spatial information they prefer to user while wayfinding, and how the components can be modified to make wayfinding in their facilities more intuitive. This is a problem identified by Beecher (2004) and Mandel (2010), but few solutions have been published. This research takes a beginning step at addressing this problem by conducting an empirical investigation into which spatial information users are actually employing as they navigate a public library facility, without assuming that signage (or any other specific component) is the most important component of a library's spatial information system. These findings are of practical value in public librarianship because they can help increase users' access to libraries' resources and services.

\section{Literature review}

\subsection{Public library facility design}

The large body of literature devoted to public library facility design shows that the field is cognizant of the importance of the facility's design for allowing users to access and use library resources and services. The majority of the literature consists of facility design guidebooks that offer step-by-step advice on designing a new, or redesigning an existing, public library facility. Whereas the academic library facility design literature also includes a subset of research conducted in and evaluations of existing facilities, the public library facility design literature largely lacks empirically-based contributions. One contribution comes from Beecher (2004), who found the literature lacked information on user preferences and attitudes toward wayfinding, issues beginning to be addressed by her study and this study.

A large focus of the public library facility design literature is on how best to allocate space within the public library facility. Models of space allocation addressed in the public 
library facility design literature include collection space needs (American Library Association, 1970; Dahlgren, 1988; Holt, 1986; Sannwald \& Smith, 1988), community needs (Brawner \& Beck, 1996; Cohen \& Cohen, 2003; Dahlgren, 1985, 1996; Jones, 2001; Lushington, 2002; Lushington \& Kusack, 1991; Nelson, Altman, \& Mayo, 2000; Public Library Association, 1979), library use measures (Brawner \& Beck, 1996; Lushington, 1987), and spatial behavior (Bryan, 2007; Cohen \& Cohen, 1978; Sannwald, 1992; Veatch, 1979). The library facility design literature includes evaluations of existing facilities, as well as suggestions for improving traffic flow, signage, and other environmental design elements. Draper and Brooks (1979) provide help for librarians faced with poor traffic flow with suggestions that involve moving furniture, and Bosman and Rusinek (1997) show that installing a few new signs and/or a floor plan can increase users' satisfaction with the library's signage system. These two solutions show the importance of understanding human spatial behavior for library facility design and how to improve the design of an existing library to facilitate human spatial behavior. The largest body of literature on public library wayfinding focuses on signage (e.g., Brown, 2002; Daniels \& Eakin, 1979; Grimley, 1974; Kosterman, 1978; Mallery \& DeVore, 1982; O’Brien, 2010; Pollet \& Haskell, 1979; Selfridge, 1979; and White, 2010) despite the argument that signage cannot compensate for ambiguous architecture (Passini, 1996).

\subsection{Wayfinding}

Passini explains the difference between spatial orientation and wayfinding: spatial orientation is about a person's "ability to mentally represent the spatial characteristics of a setting" and "to situate him or herself within that representation" (1996, p. 321) and wayfinding is broader as it "includes all the mental processes which are involved in purposeful mobility" (1996, p. 322). There are three such processes, making a decision, executing a decision, and processing information needed to make and execute decisions. Wayfinding research began in the external built environment (cities), with Kevin Lynch's The Image of the City (1960). The internal built environment (constructed facilities) has become the focus of additional wayfinding research (cf. Baskaya, Wilson, \& Özcan, 2004; Best, 1970; Dogu \& Erkip, 2000; Haq \& Zimring, 2003). When people navigate the built environment and struggle to orient themselves,

find the appropriate path, or become lost, they suffer frustration, stress, and aggravation, and can blame themselves, and feel stupid, anxious, and angry (Arthur \& Passini, 1992). Designing the built environment with human wayfinding in mind can reduce these negative reactions by 
allowing people to find their ways intuitively, while also reducing functional inefficiency and increasing accessibility and safety (Passini, 1996). These factors are critical for public libraries, built environments in which people enter who already may be frustrated by a lack of information or knowledge and are concentrating on finding the cues they need to solve their information problems rather than their wayfinding problems.

Wayfinding research generally is conducted in large, complex public facilities, such as municipal buildings (Best, 1970), hospitals (Baskaya et al., 2004), shopping malls (Chebat, Gélinas-Chebat, \& Therrien, 2005; Dogu \& Erkip, 2000; Haq \& Zimring, 2003), museums (Bitgood, 2006; Cosley et al., 2009), and airports (Churchill, Dada, de Barros, \& Wirasinghe, 2008). Public libraries are large, complex built environments that share much in common with environments like shopping malls and hospitals. In all of these facilities, users enter the facilities seeking to fulfill specific needs, and their focus on those goals distracts them from paying complete attention to the facilities and their architectural cues. Downs (1979) explains that the library is an architectural maze in which improved wayfinding can increase the effectiveness, frequency, and volume of library use and therefore should be considered when arranging interior spaces.

The literature on library facility design indicates this need. Beck (1996) finds that library users are cognitively complex and designers should take into account the needs of users of different age groups and physical abilities. Understanding traffic flow and identifying problems with that flow (Draper \& Brooks, 1979), as well as tracking the behavior of real users through a facility (Lushington, 2002), are critical to effective library wayfinding design. Mandel (2010) found that observing users as they navigate an area of the facility allows a library's staff to identify high-traffic areas, where they can focus redesign efforts. This is particularly critical as a component of post-occupancy evaluation, as "it is difficult to predict the public's navigational patterns or to know what directional cues visitors will need before the building is put to use" (Mattern, 2007, p. 81). Yet, there is more emphasis on designing more effective library signage systems (Bosman \& Rusinek, 1997; Brown, 2002; Byam, 1979; Daniels \& Eakin, 1979; Loomis \& Parsons, 1979; Pollet \& Haskell, 1979) than conducting empirical studies designed to understand how users wayfind in a public library facility (Beecher, 2004; Mandel, 2010).

\subsection{Conceptual framework}


Passini observed that the wayfinder develops his decision plan according to five problemspecific strategies and employing two user-specific styles that he detailed in his "Conceptual Framework of Wayfinding" (1981), which guides this research. Passini sees the wayfinding decision plan as a structured process that operates at different levels of generality, through which the wayfinder focuses on individual tasks or subtasks always while considering the problem as a whole (Strategy 1: Dividing the Task into Manageable Parts While Keeping an Eye on the Larger Task at Hand). But, he can only deal with one problem or subtask at a time (Strategy 2: Narrowing), following a continuous process that can deal with unforeseen problems whenever they occur, pointing to the dynamic property of decision making (Strategy 3: Adapting and Responding). For as large a part of the decision plan as possible, the wayfinder relies on an existing solution repertoire (Strategy 4: Accessing One's Schemata). He also bases his plan on the available environmental information (Strategy 5: Gathering Information and Adapting Accordingly). The purpose of understanding these strategies is to use them to identify where the decision points are along users' routes and to provide the information needed at these points for users to make the necessary decisions (Passini, 1996).

Passini (1981) also observed two distinct wayfinding styles defined by the type of information on which each relies: linear and spatial. The linear wayfinding style relies on the signage system, which Passini defines as a linearly organized wayfinding support system (i.e., one that progresses from one location to another). The spatial wayfinding style relies on the wayfinder's spatial understanding of the setting, which is influenced by his familiarity with the setting, architectural legibility of the setting, and wayfinding cues and tools that are available in the setting, such as maps and floor plans. The styles guide a wayfinder's overall decisionmaking system, whereas the strategies are employed at decision points along the route.

More than a decade after positing this framework, Passini addressed the issue of universality in decision-making (1996). He explained that decisions about which routes to choose are not central issues for wayfinding design. Rather, wayfinding design assumes that varied users will make similar decisions along a route "in settings where adequate information is provided" (p. 323). However, settings that are ambiguous lead to a higher rate of variation in decision-making. Beecher (2004) found that ambiguity also contributes to user frustration and inability to solve information problems. These negative consequences of ambiguous design support Passini's argument that it is unwise to blame the users themselves for their wayfinding 
challenges; "the architect also determines the nature of the wayfinding problems future users will have to solve" (1996, p. 323). The idea is that planning for people's real behavior can result in facilities that are unambiguous, where people are making similar decisions, allowing for more universal design and placement of spatial information cues. As public libraries attempt to plan for user's behavior in the real world of a library and unambiguous facilities, it is this concept of wayfinding design that plans for users' behavior in the real facility that prompted the researcher to investigate the applicability of Passini's conceptual framework to public library facility design.

\section{Method}

A pilot study was conducted at a medium-sized public library (one serving a population between 25,000 and 100,000 residents) in which the researcher observed library users as they entered the facility, and recorded their entry routes on copies of the library floor plan (Mandel, 2010). A major limitation of that pilot study was the inability to speak to library users to ascertain their thoughts, opinions, and satisfaction with the library's wayfinding system, limitations noted to be prevalent in the literature (Beecher, 2004). Therefore, this follow-up study employed a multi-method case study research design, guided by Passini's framework (1981), to investigate library user wayfinding behavior within the entry area of a medium-sized public library facility. The facility chosen as the research site is a two-story public library building with a second-floor mezzanine wrapping around the first floor (the library). The mezzanine allowed the researcher to sit at the reception desk on the east end of the second floor with an unrestricted view of the two public entrances, circulation desk, and entry areas of the facility, which were defined as the visible portion of the first floor (i.e., not including the areas below where the researcher sat on the mezzanine). To compare users' wayfinding behaviors across the major seasons of library services, which correspond with the area's public school calendar, the research was conducted during three weeks — one each in spring, summer, and fall.

\subsection{Research Questions}

RQ1. To what degree is user wayfinding behavior in the entry area of a medium-sized public library facility consistent over time (i.e., from spring to summer to fall)?

RQ2. How do library users navigate beyond the main entrance, specifically, what routes do users of this library facility travel from the entrance and through the entry area? 
RQ3. How do users describe the routes they take from the entrance of the facility, what reasons do they give for taking these routes, and to what degree do these described routes match (or not) the most popular routes observed in the library?

RQ4. Which of Passini's five wayfinding strategies (if any) are library users employing to navigate through the entry area of the facility: dividing the task into manageable parts while keeping an eye on the larger task at hand, narrowing, adapting and responding, accessing one's schemata, or gathering information and adapting accordingly?

RQ5. Which of Passini's two wayfinding styles (if any), or some combination of both, are library users employing to navigate through the entry area of the facility: reliance on the linear style through usage of the facility's signage system, or reliance on the spatial style through the user's spatial understanding of the library setting, including the user's familiarity with, architectural legibility of, and wayfinding cues and tools available in the setting?

RQ6. In what ways (if any) would library users alter the library's wayfinding system, for example widening pathways, adding or changing signage, or other recommendations?

\subsection{Research design}

The case study research design included document review of the library's wayfinding information system to understand the research setting - floor plans, maps, signage, and other tools available to users in the library; unobtrusive observation of library user wayfinding behavior in the entry area of the library with observed routes traced on copies of the library's floor plan to address RQ1 and RQ2; intensive interviews with 16 library users to discuss their views on wayfinding in the library to address RQ3, RQ4, RQ5, and RQ6; and an expert review with library staff and a library wayfinding and signage expert to validate research findings. Observation occurred during three weeks, one each in spring, summer, and fall, with weeks selected purposively to be representative of the levels of use of the facility in each season. The case study design provided the ability to analyze data gathered from different methods, thereby mitigating the limitations of the single-method pilot study (Mandel, 2010), strengthening the findings, and providing a more comprehensive view of library user wayfinding behavior than was obtained from the single-method pilot study (Mandel, 2010). Significant detail on the method is available elsewhere (Mandel, 2012).

\subsection{Data analysis}


Data analysis for this case study involved three major analytic techniques: geospatial analysis, content analysis, and data integration. The researcher employed geospatial analysis for the routes identified from unobtrusive observation and user interviews (using thematic analysis), thematic content analysis for the wayfinding tools identified in the document review and expert review interviews, and conceptual content analysis of the transcripts of user interviews.

Each observed user was assigned a case number by which all nodes (stops) and segments (portions of a route that connect one node to another node) of his or her entry route were entered into a GIS database and subsequently analyzed. Each floor plan worksheet was assessed visually to compare the observed path with previously identified nodes and segments. If the node or segment matched a previously identified one, the case was entered into an Excel spreadsheet with the corresponding node and segment numbers. If the node or segment did not match any identified nodes or segments, a new node or segment was drawn in ArcMap and assigned the next numerical node or segment identifier. Then the case was entered into the database with all corresponding identified node and segment numbers. Although interviewees were asked to trace their entry routes on copies of the floor plan data collection instrument, these maps were imprecise and impossible to code and map via the GIS. Therefore, interviewees' routes were analyzed thematically to determine nodes and general paths interviewees indicated using.

The researcher conducted thematic content analysis of the wayfinding information system tools from the document review and notes and recordings from the expert review and conceptual content analysis of the transcripts of intensive interviews with library users. Content analysis is a systematic, objective, quantitative analysis of message characteristics that is useful for examining trends and patterns in documents (Schutt, 2006). As such, it is a valuable tool for analyzing the content of reviewed documents and interview transcripts. The researcher analyzed the wayfinding information system tools, then the interviews with library users. No pre-defined coding scheme existed that could guide this analysis, so the coding scheme began with Passini's (1981) wayfinding styles and strategies and developed iteratively as the researcher coded the documents and interview transcripts.

A strength of the case study approach is the opportunity to integrate data collected from multiple methods (Yin, 1984). In this research, data integration included four comparisons:

1. Observed routes with interviewees' traced routes to determine the degree to which interviewees indicated using the most popular observed routes - this comparison measure 
proved ineffective as interviewees drew imprecise and potentially inaccurate routes (many indicated they were not 100\% sure of their recollections);

2. Observed popular routes and high-traffic areas and interviewees' explanations of why they choose their entry routes;

3. Data gathered from the document review about what kinds of information are available in the library's wayfinding system and the wayfinding styles and strategies interviewees indicated they use; and

4. Interviewees' indications of their usage of Passini's wayfinding styles and strategies (1981) and observed behaviors that related to Passini's wayfinding styles and strategies. Data integration also included an overall analysis of all data to obtain the most comprehensive picture possible of user wayfinding behavior in the entrance area of the library.

\subsection{Limitations and data quality}

This research included four data collection techniques, and the goal of using these techniques was to increase the validity of the overall research findings. In addition, this research included an expert review that allowed a check of the face validity of the research findings, with experts concluding that the findings are valid. All of the participating experts concurred that the findings were reasonable and valid on their face, with the library wayfinding and signage expert saying the findings matched what she expected to find in a public library. The experts also reviewed the data for any potential bias the researcher introduced into the research, not finding any such bias.

The unobtrusive observation data was subjected to inter-observer testing of recording accuracy for traced routes and intra- and inter-coder reliability testing for assignment of route identifiers to observed routes. Intra-coder reliability measured $\kappa=.977$ and inter-coder reliability measured $\kappa=.924$, both "almost perfect" reliability (Landis \& Koch, 1977, p. 165). User interview transcripts were subjected to intra- and inter-coder testing, and translated transcripts (from Spanish to English) were spot-checked for accuracy of translation. Intra-coder reliability measured at $\kappa=.648$ and inter-coder reliability measured at $\kappa=.529$, which are “substantial" and "moderate" agreement, respectively (Landis \& Koch, 1977, p. 165).

The focus of this case study was on one library in one place at one time. The results could not be and were not generalized beyond that focus. There is potential for replicating the research at other libraries and information organizations (e.g., museums or bookstores) in other 
geographic settings to attempt to develop the transferability of the results, but that was not the focus of the study and would require follow-up research. In addition, participation in the study was of a voluntary nature, so it is possible that only people with stronger or positive opinions might have chosen to participate, and people might have been untruthful in their responses to the interviewers' questions.

\section{Results}

\subsection{A picture of the library's wayfinding system}

Sign quality was not a major problem with the signage system in the Library. However, the sheer volume of signage could be problematic. At any given time, the library had approximately 1300-1400 signs, which the library wayfinding and signage expert identified to be a large number given the size of the facility. Passini explains that information overload is common in complex facilities (1996), and in fact, interviewees indicated that there were too many signs in the library, causing the signs to become "white noise" that users ignored while wayfinding in the facility. Directional and regulatory signs were underrepresented among the signage, comprising slightly less than one-quarter of all signs in the Library. Directional signs assist users' orientation and navigation, so they might be more important to easing wayfinding than informational signs, which comprised over three-quarters of all signs in the library. Also, many informational signs duplicated each other; for example, in the non-fiction stacks, there were many instances of multiple signs indicating the same subject term. Such duplication results in the information overload referred to by Passini (1996) and a situation in which it does not matter where a sign is located since users are simply ignoring the signs altogether.

\subsection{Observed user wayfinding behavior}

Observation focused primarily on users' routes, including all nodes within the routes and the segments connecting the nodes, with analysis focusing on nodes and segments rather than complete routes. The researcher also noted all observed wayfinding behaviors, such as looking at signs or asking for directions (when an observed wayfinder approached a staff member and the interaction included the staff member pointing toward another area of the library, this was assumed to be an instance of the wayfinder asking for directions). The researcher observed users engaging in 11 distinct wayfinding behaviors as they navigated the library entry area; the most frequently observed were looked around $(n=40 ; 14.0 \%)$, followed or joined another person $(n=$ 
$20 ; 7.0 \%)$, got directions from another person, either staff or another library user $(n=16 ; 5.6 \%)$, and made a U-turn $(n=16 ; 5.6 \%)$.

Wayfinders were observed to connect the same two nodes in variant ways. In slightly more than half of node-to-node connections ( $n=55 ; 52.9 \%$ ), all observed wayfinders used the same connecting segment. In the remaining cases $(n=49 ; 47.1 \%)$, different people were observed making the same node-to-node connections using different connecting segments. In many of these instances, only two different connecting segments were observed, but in a few cases, three or more connecting segments were observed. When a node-to-node connection was observed with multiple connecting segments, one of those segments was a predominant segment that was observed to connect those nodes more frequently than any other segments connecting those nodes.

This was most clearly visible in the node-to-node connection between the east entrance and the circulation line (Figure 1). Although this node-to-node connection was observed 38 times with two different connecting segments, 37 cases took the same connecting segment and only one case navigated a different connecting segment between the two nodes. The segment taken by the majority of cases (S003 in the figure) was the shorter and more direct segment versus the alternate connecting segment (S062 in the figure). This pattern was visible also in node-to-node connections observed 11-15 $(n=5)$ and 6-10 times $(n=10)$. 


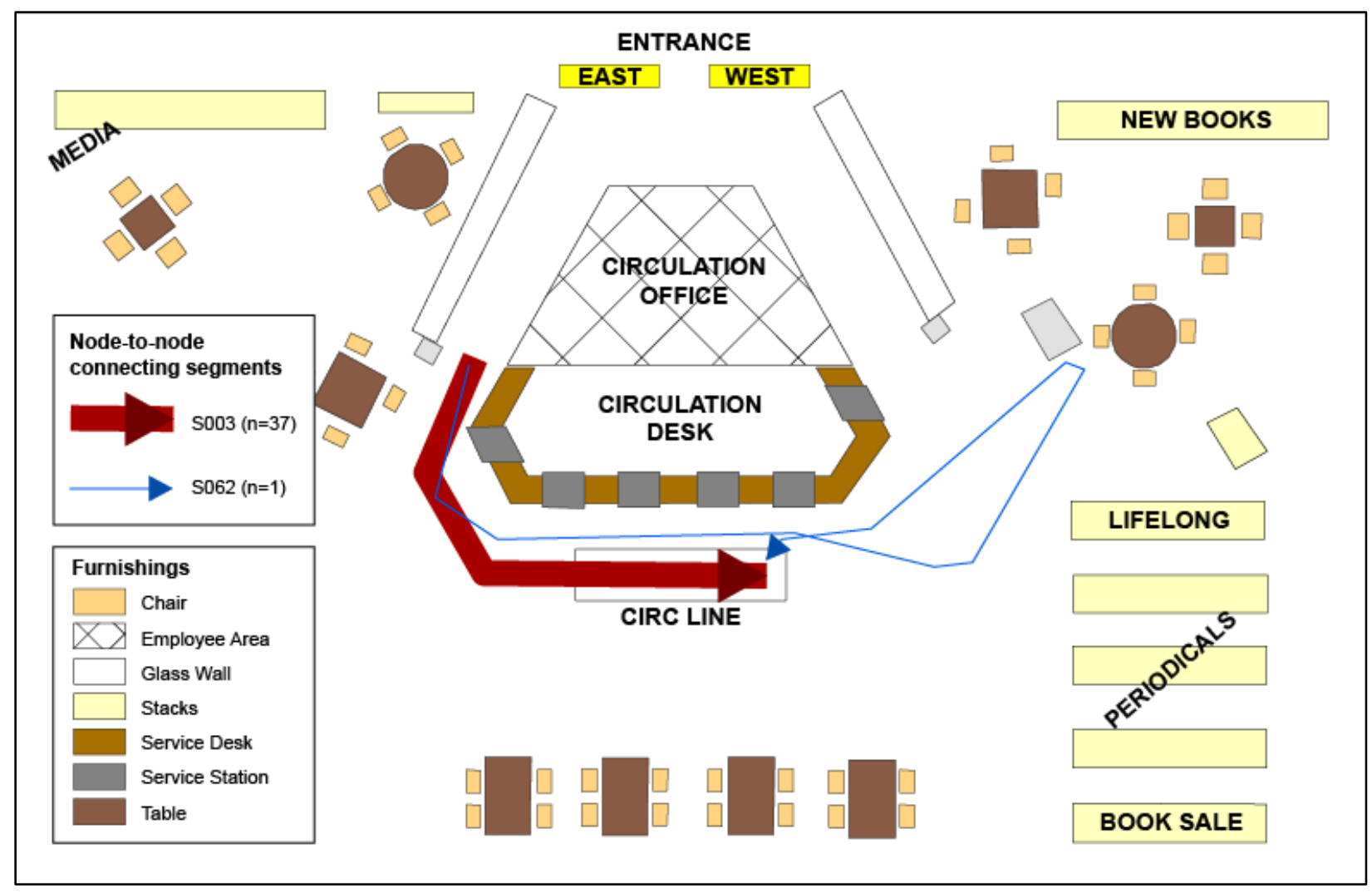

Figure 1: Frequencies of observation of the different segments connecting the east entrance and the circulation line.

\subsection{Users' descriptions of their wayfinding behavior}

The most popular observed segments beginning at one of the entry doors connected the east entry door to the circulation line or circulation desk. However, interviewees rarely indicated that the circulation desk was their first stop $(n=2)$. Interviewees described taking different routes in the library depending on the purpose of their visits. For example, people who said they came to the library with and without their children altered their routes depending on whether their children were with them. Routes also varied based on interviewees' information needs, with one interviewee saying "Mmm... sometimes I use the reference... uh... computer, and, uh if I'm studying, I like the room, the quiet room over there in the back... And sometimes, depending how I feel, I go to the kids' books.” Reasons for taking specific routes included shortest $(n=1$; percentages are not provided because some interviewees provided more than one reason and percentages would exceed $100 \%)$, straightest $(n=2)$, or easiest route $(n=2)$; habit $(n$ 
$=5)$; because the route passed the materials they needed $(n=3)$; and to avoid obstacles $(n=1)$. Three people did not know why they navigated the route they described.

Interview transcripts were coded with Passini's strategies and styles in mind in an attempt to identify if Passini's strategies related in any reliable way to the ways in which library users were making decisions while wayfinding. Interviewees indicated using Strategies $3(n=9), 4(n$ $=5)$, and $5(n=5)$. Strategies 1 and 2 were never mentioned. As compared to the five wayfinding strategies, interviewees indicated high levels of use of Passini's two wayfinding styles to guide their overall system of wayfinding. Style 1 (linear, the signage system) and Style 2 (ppatial, wayfinding cues and tools) were mentioned by nearly all interviewees ( $n=9$ and $n=$ 16 , respectively). It seems interviewees were more likely to recall and mention use of the wayfinding styles than the wayfinding strategies; potential reasons for this are discussed in sections 5.4 and 5.5 .

The majority of recommendations from interviewees for altering the library's wayfinding system related either to the signage system or the pathways. On the whole, interviewees indicated they were pleased with the library and their ability to find things in it, even when they also described times they had gotten lost, could not find something, or had trouble understanding the call number system. Five people specifically said there was no need to alter the pathways and two said the same about the signage. Those people who did indicate that there was something that could be improved about the library's wayfinding system seemed equally desirous of changes to the signage system as to the pathways. The most frequent request was for straighter (more direct) pathways ( $n=8$; percentages are not provided because many respondents indicated more than one suggestion). Other common requests were for use of color to differentiate categories on signs $(n=5)$, larger signs $(n=2)$, and a variety of other changes to signs.

\section{Discussion}

\subsection{Consistency of user wayfinding behavior over time}

Overall, whether looking at frequency of observation of particular segments or observed wayfinding behaviors, library users' wayfinding behavior is generally inconsistent over time. However, when looking at high-traffic areas, there is some consistency, which was indicated in the pilot study as well (Mandel, 2010). So, the real consistencies over time are the high-traffic 
areas and that library users' wayfinding behavior tends to vary-by use of segments and by use of observed wayfinding behaviors.

\subsection{User navigation in the library entry area}

Of people connecting the same two nodes, some were very consistent in using the predominant segment (the one used most frequently) or other connecting segments used multiple times. Others deviated from the majority in that they used an unpopular segment to connect the two nodes. In general, a predominant segment tends to be the straightest or most direct segment connecting two given nodes, which may be a reason behind some consistency of library user wayfinding behavior. However, deviation from or inconsistency with these more direct, predominant segments does not necessarily indicate wayfinding failure (i.e., not finding the intended destination). Guided by a theory that assumes a known destination (Passini, 1981), this research cannot explain why some users choose less direct segments, and it is possible they are browsing, engaging in serendipitous information seeking - a method noted by Foster and Ford (2003) and Spink (2003), or performing other activities with a less-defined purpose, such as berrypicking (Bates, 1989).

Another possibility is that library users' wayfinding behavior varies depending on whether the wayfinder is alone or with another person. Interviewees indicated this to be the case as many answered in multiple parts, providing different routes they use when they come to the library alone or with different other people. For example, people who said they come to the library with and without their children alter their routes depending on whether their children are with them. Unobtrusive observation also indicates that navigating with another person likely alters routes. People who followed or joined another person were more likely to navigate routes with five or more stops than people who navigated alone. Overall, and as noted above, library users were observed to be both consistent and inconsistent in their wayfinding behaviors through the library entry area.

\subsection{Description of users' routes in the Library entry area}

Overall, library users describe routes that pass similar nodes as those observed during the unobtrusive observation. However, the order in which they visit the nodes seems different. While many users were observed to visit the circulation line or circulation desk first, only two interviewees indicated circulation as their first stop in the library. Reasons for this discrepancy are unknown, but possibilities include the interviewees' general difficulty in describing their 
entry area routes and the fact that many interviewees indicated they used the computers or study areas more than the library's materials. Interviewees' struggles with recalling their typical routes point to a need for further research that asks people to navigate while they are observed and while they think aloud. Such research may allow further investigation into resolving these discrepancies.

\subsection{Use of Passini's wayfinding strategies}

Based on the interviews and unobtrusive observation, one might conclude that Passini's (1981) wayfinding strategies are not employed by the majority of users as they make decisions while wayfinding in the library, especially Strategies 1 and 2, which were neither observed nor mentioned by interviewees. However, given the difficulty in ascertaining cognitive behaviors through physical observation or recollection during interviews, this cannot (and should not) be taken as a certainty. What this research does show is that wayfinders are using Passini's strategies to some degree to guide their decision-making. As this research is meant to be exploratory and does show users to be applying the strategies to wayfinding decision-making to some degree, additional research is necessary to test the use of these strategies among public library users more fully. One possible approach is an experiment employing think aloud protocol to try to get at wayfinders' thoughts as they occur. Any such research also should consider the additional wayfinding decision-making behaviors identified in this study that differ from Passini's strategies.

\subsection{Use of Passini's wayfinding styles}

Overall, it seems that library users employ Passini’s (1981) wayfinding styles more often than his wayfinding strategies. Of course, this finding is predicated upon limitations such as the inability to physically observe the cognitive processes involved in using the strategies to guide decision-making and the challenges for interviewees in recalling these cognitive processes. Also, the styles are meant to describe a person's overall wayfinding methodology, and it is possible people are more cognizant of or able to articulate their broad methodology of wayfinding as compared to the cognitive processes they use in making specific wayfinding decisions. While the styles are used by library wayfinders, the library signage system may be hindering full use of the linear style (i.e., signage) in this facility. The library's excessive signage is seen as blending into the background and, as Passini explains (1996), excessive 
signage located in areas other than where users need to make wayfinding decisions results in information overload and use of something else to guide one's wayfinding behavior.

5.6 User-recommended modifications to the Library's wayfinding system

Although many users seem to struggle with wayfinding in the library, including interviewees who indicated problems finding what they sought and observed wayfinders who made U-turns or appeared to be lost or wandering, this does not seem to translate into recommended changes to improve the library's wayfinding system. There are two key possible explanations for this. First, it is possible that interviewees were uncomfortable indicating that anything was wrong if they were trying to provide the answer they thought was expected - that nothing is wrong. This is known as agreement bias (Schutt, 2006), and the researcher attempted to minimize it by stressing she was not working for or representing the library. Second, they might know something is wrong because they struggle to wayfind, but they might not know how to modify the library's wayfinding system to facilitate easier wayfinding. In either case, it is clear that just because people struggle to wayfind in the library does not mean they will say things need to change.

\section{Directions for Future Research}

This study identified three main areas for future research: research for libraries and information organizations, wayfinding, and Passini's conceptual framework. A selection of future research areas include, but is not limited to:

- How many signs should there be in a library, to what degree are wayfinders using them, which types of signs (e.g., area signs, call number signs, etc.) are wayfinders using most and least and why?

- What is the degree of difference between how much wayfinding matters to new users unfamiliar with a library building versus regular users of that facility and in what ways is wayfinding behavior related to users' goals for using the library facility?

- Why are some areas of a facility experiencing higher levels of traffic than other areas?

- To what degree are users stopping at specific nodes for specific reasons, what are those reasons, and to what extent does this affect their overall wayfinding behavior?

- What are the motivations behind different wayfinding behaviors, such as why do some users use more direct paths and others meander? To what degree are these different 
behaviors related to the users' goals for using the facility, such as having an intended destination vs. intending to browse?

- If users were given a wayfinding task to complete in a facility and asked to think aloud while completing the task, which (if any) of Passini's styles and/or strategies would they use to complete the task? Does the type of task affect which of the styles and/or strategies wayfinders use?

- If the styles and strategies were explained to wayfinders, to what degree would they understand what the styles and strategies mean and realize that they are or are not using the styles and strategies while they wayfind?

Future research could incorporate use of additional technologies for recording user wayfinding behavior, such as asking users to wear RFID tags, carry GPS-enabled smart phones with a special app (application), or use scanning apps enabled by smart phone cameras (such as QR code scanners) to "check in" to specific places as they wayfind in a facility.

\section{Conclusion}

Despite the increasing shift toward digital services, the facility remains crucial to the daily operation of a public library. Library facility research tends to occur in academic libraries, or when it is in public libraries, such research is often aimed at practitioner journals, is not theoretically based, and pays minimal attention (if any) to user wayfinding needs. However, it is critical for public library facility designers to understand how users actually orient and navigate in public library facilities in order to design public library facilities that make it easy and intuitive for users to wayfind in them.

Successful wayfinding relies on a facility to provide sufficient, effective, and opportunely-located spatial information to solve wayfinding problems. This is akin to how information-seeking relies on a library or other information organization to provide sufficient, effective, and opportunely-located information to solve information needs. Whether a user has an intended destination in mind or not, when he wayfinds in a facility, he requires the facility to provide all the spatial information he needs to solve his wayfinding problem(s). Without research into what those problems are and the types of information needed to solve them in public libraries, public library facilities are unlikely to be designed in ways that facilitate user wayfinding. 
This study is a step in the direction of developing a body of empirical, theoretically guided research into public library facility design and evaluation that emphasizes investigation of user wayfinding behaviors as a guide to designing facilities that users can navigate intuitively. While additional work still needs to be done, and that work is varied in the types of research questions that may be asked (such as the questions posed above), the critical point is that the work is necessary. The ability to evaluate the degree to which a public library facilitates wayfinding can lead to a facility that improves delivery of public library services and access to library resources. Improved wayfinding information systems in public library facilities can lessen user information-seeking frustration in complicated, mazelike libraries, especially as libraries cut service hours in the wake of budget cuts, leaving users less time to search the libraries to find the information and resources they need. Second, improved wayfinding systems can ease the burden on libraries' staffs to direct users to different areas of the libraries that users could find for themselves if the libraries' wayfinding systems were more intuitive and selfexplanatory, as a labyrinth should be. Also, improving libraries' wayfinding systems can improve the overall findability of information and resources stored in the libraries, helping users find information they might otherwise miss. All of this can increase users' levels of satisfaction with public library facilities, and with public libraries as organizations. 


\section{References}

American Library Association, Library Administration Division, Ad Hoc Committee on the Physical Facilities of Libraries. (1970). Measurement and comparison of physical facilities for libraries. Chicago, IL: American Library Association.

Arthur, P., \& Passini, R. (1992). Wayfinding: People, signs, and architecture. New York, NY: McGraw-Hill.

Baskaya, A., Wilson, C., \& Özcan, Y. (2004). Wayfinding in an unfamiliar environment: Different spatial settings of two polyclinics. Environment and Behavior, 36(6), 839-867. doi: $10.1177 / 0013916504265445$

Bates, M. J. (1989). The design of browsing and berrypicking techniques for the online search interface. Retrieved from http://pages.gseis.ucla.edu/faculty/bates/berrypicking.html

Beck, S. G. (1996). Wayfinding in libraries. Library Hi Tech, 14(1), 27-36.

Beecher, A. B. (2004). Wayfinding tools in public library buildings: A multiple case study (Unpublished doctoral dissertation). University of North Texas, Denton, TX.

Best, G. (1970). Direction-finding in large buildings. In D.V. Canter (Ed.), Architectural psychology: Proceedings of the conference held at Dalandhui University of Strathclyde, 28 February - 2 March 1969 (pp. 72-75). Cambridge, England: W. Heffer and Sons.

Bitgood, S. (2006). An analysis of visitor circulation: Movement patterns and the general value principle. Curator, 49(4), 463-475. Retrieved from http://www.curatorjournal.org/

Bosman, E., \& Rusinek, C. (1997). Creating the user-friendly library by evaluating patron perceptions of signage. Reference Services Review, 25(1), 71-82. Retrieved from http://www.emeraldinsight.com/Insight/viewContainer.do?containerType=JOURNAL\&c ontainerId $=11304$

Brawner, L. B., \& Beck, D. K., Jr. (1996). Determining your public library's future size: A needs assessment and planning model. Chicago, IL: American Library Association.

Brown, C. R. (2002). Signs and wayfinding. In C. R. Brown, Interior design for libraries: Drawing on function and appeal (pp. 87-95). Chicago, IL: American Library Association.

Bryan, C. (2007). Managing facilities for results: Optimizing space for services. Chicago, IL: American Library Association.

Byam, M. S. (1979). An approach to public library signage. In D. Pollet \& P. C, Haskell (Eds.), Sign systems for libraries: Solving the problem (pp. 137-144). New York, NY: R. R. Bowker. 
Chebat, J.-C., Gélinas-Chebat, C., \& Therrien, K. (2005). Lost in a mall, the effects of gender, familiarity with the shopping mall and the shopping values on the shoppers' way finding processes. Journal of Business Research, 58, 1590-1598.

doi:doi:10.1016/j.jbusres.2004.02.006

Churchill, A., Dada, E., de Barros, A. G., \& Wirasinghe, S. C. (2009). Quantifying and validating measures of airport terminal wayfinding. Journal of Air Transport Management, 14, 151-158. doi:10.1016/j.jairtraman.2008.03.005

Cohen, A., \& Cohen, E. (1978). Behavioral space planning and practical design for libraries. New York, NY: Aaron Cohen \& Associates.

Cohen, A., \& Cohen, E. (2003). Library architecture and interior design. In Encyclopedia of library and information science [electronic version] (pp. 1578-1584). New York, NY: Marcel Dekker.

Cosley, D., Baxter, J., Lee, S., Alson, B., Nomura, S., Adams, P., Sarabu, C., \& Gay. G. (2009). A tag in the hand: Supporting semantic, social, and spatial navigation in museums. In Proceedings of CHI 2009, 1953-1962. doi:10.1145/1518701.1518999

Dahlgren, A. C. (1985). Planning the small public library building. Chicago, IL: American Library Association, Library Administration and Management Association.

Dahlgren, A. C. (1988). Public library space needs: A planning outline. Madison, WI: Department of Public Instruction.

Dahlgren, A. C. (1996). Planning the small library facility (2nd ed.). Chicago, IL : American Library Association, Library Administration and Management Association.

Daniels, B., \& Eakin, G. (1979). Coordinating graphics and architecture. In D. Pollet \& P. C. Haskell (Eds.), Sign systems for libraries: Solving the problem (pp. 181-185). New York, NY: R. R. Bowker.

Dogu, U., \& Erkip, F. (2000). Spatial factors affecting wayfinding and orientation: A case study in a shopping mall. Environment and Behavior, 32(6), 731-755.

Downs, R. M. (1979). Mazes, minds, and maps. In D. Pollet \& P. C. Haskell (Eds.), Sign systems for libraries: Solving the problem (pp. 17-32). New York, NY: R. R. Bowker.

Draper, J., \& Brooks, J. (1979). Directing traffic. In J. Draper \& J. Brooks, Interior design for libraries (pp. 26-39). Chicago, IL: American Library Association.

Foster, A., \& Ford, N. (2003). Serendipity and information seeking: An empirical study. Journal of Documentation, 59(3), 321-340. doi:10.1108/00220410310472518 
Grimley, S. (1974). Signs and graphic displays: A survey of their use in public libraries (Unpublished doctoral dissertation). The University of Chicago, Chicago, IL.

Haq, S., \& Zimring, C. (2003). Just down the road a piece: The development of topological knowledge of building layouts. Environment and Behavior, 35(1), 132-160. doi:10.1177/0013916502238868

Holt, R. M. (Ed.). (1986). Turning needs into space requirements: The public library. In R. M. Holt (Ed.) Talking buildings: A practical dialogue on programming and planning library buildings: Proceedings of a building workshop (Pasadena, CA, October 3-4, 1986) (pp. 45-63). Del Mar, CA: Raymond M. Holt and Associates. (ERIC Document Reproduction Service No. ED271109)

Jones, D. (2001). People places: Public library buildings for the new millennium. Australasian Public Libraries and Information Services, 14(3), 81-89. Retrieved from http://www.auslib.com.au/periodicals.htm

Kern, H. (2000). Through the labyrinth: Designs and meanings over 5000 years. Munich, Germany: Prestel.

Kosterman, W. (1978). A guide to library environmental graphics. Library Technology Reports, 14(3), 269-291.

Landis, J. R., \& Koch, G. G. (1977). The measurement of observer agreement for categorical data. Biometrics, 33(1), 159-174.

Loomis, R. J., \& Parsons, M. B. (1979). Orientation needs and the library setting. In D. Pollet \& P. C. Haskell (Eds.), Sign systems for libraries: Solving the problem (pp. 3-15). New York, NY: R. R. Bowker.

Lushington, N. (1987). Output measures and library space planning. Library Trends, 36(2), 391398.

Lushington, N. (2002). Libraries designed for users: A 21st century guide. New York, NY: NealSchuman.

Lushington, N., \& Kusack, J. M. (1991). The design and evaluation of public library buildings. Hamden, CT: Library Professional.

Lynch, K. (1960). The image of the city. Cambridge, MA: Massachusetts Institute of Technology Press.

Mallery, M. S., \& DeVore, R. E. (1982). A sign system for libraries. Chicago, IL: American Library Association. 
Mandel, L. H. (2010). Toward an understanding of library patron wayfinding: Observing patrons' entry routes in a public library. Library and Information Science Research, 32, 116-130. doi:10.1016/j.lisr.2009.12.004

Mandel, L. H. (2012). Lost in the labyrinthine library: A multi-method case study investigating public library user wayfinding behavior (Doctoral dissertation). Available from ProQuest Dissertations and Theses database. (UMI No. 3519349)

Mattern, S. (2007). Form for function: The architecture of new libraries. In S. Mattern, The new downtown library: Designing with communities (pp. 55-83). Minneapolis, MN: University of Minnesota Press.

Nelson, S., Altman, E., \& Mayo, D. (2000). Managing for results: Effective resource allocation for public libraries. Chicago, IL: American Library Association.

O'Brien, D. (2010). Wayfinding and signage. In Encyclopedia of Library and Information Sciences (3rd ed.) (pp. 5593-5614). doi:10.1081/E-ELIS3-120044069

Passini, R. (1981). Wayfinding: A conceptual framework. Urban Ecology, 5, 17-31.

Passini, R. (1996). Wayfinding design: Logic, application and some thoughts on universality. Design Studies, 17, 319-331.

Pollet, D., \& Haskell, P. C. (1979). Introduction. In D. Pollet \& P. C. Haskell (Eds.), Sign systems for libraries: Solving the problem (pp. ix-xii). New York, NY: R. R. Bowker.

Public Library Association, Goals, Guidelines, and Standards Committee. (1979). The public library mission statement and its imperatives for service. Chicago, IL: American Library Association.

Sannwald, W. W. (1992). Functional requirement and space relationships. In R. G. Martin (Ed.), Libraries for the future: Planning buildings that work: Papers from the LAMA Library Buildings Preconference, June 27-28, 1991 (pp. 59-72). Chicago, IL: American Library Association, Library Administration and Management Association.

Sannwald, W. W., \& Smith, R. S. (Eds.). (1988). Checklist of library building design considerations. Chicago, IL: Library Administration and Management Association division of American Library Association.

Schutt, R. K. (2006). Investigating the social world: The process and practice of research (5th ed.). Thousand Oaks, CA: Sage.

Selfridge, K. M. (1979). Planning library signage systems. In D. Pollet \& P. C. Haskell (Eds.), Sign systems for libraries: Solving the problem (pp. 49-67). New York, NY: R. R. Bowker. 
Spink, A. (2003). Multitasking information behavior and information task switching: An exploratory study. Journal of Documentation, 60(4), 336-351.

doi:10.1108/00220410410548126

Veatch, J. L., Jr. (1979). Library architecture and environmental design: The application of selected environmental design factors to the planning of public library facilities (Unpublished doctoral dissertation). Florida State University, Tallahassee, FL.

White, L. L. (2010). Better none than bad: When it comes to signage, nix the negative. American Libraries, 41(8), 23.

Yin, R. K. (1984). Case study research: design and methods. Beverly Hills, CA: Sage. 